\title{
Innovative Industrial Design
}

\author{
$\mathrm{Wu}$ Tao \\ Jiangxi College Of Foreign Studies
}

\begin{abstract}
With the informationization development of the 21st century knowledge economy, e-commerce has more and more close relationship with our study, work and life. Objective: It is necessary to explore the evolution direction of industrial design in the post industrial age to adapt to the electronic commerce era and to give new meaning to product design. Method: decompose the process of the industrial design for business services. This paper discusses the behavior patterns and consumer features of online shopping consumers, studies the advantages and disadvantages of e-commerce, and seeks the feasibility of the combination of industrial design and e-commerce in many aspects. Solution: In the era of electronic commerce, product designers can get more accurate and real product information feedback from electric business platform, find out new areas in interactive interfaces and extend the new business models.
\end{abstract}

Keywords-Electronic commerce; Industrial design; Product design; Interaction

\section{INTRODUCTION}

The production of product design information is originated in the transformation of the design data. The product design information in the past only stayed in the application mode of the data level. However, the product design information today then progresses the so-called information level (there are inheritance order and relationships between data). And in the era of knowledge economy in the future, it will be up to the knowledge hierarchy (has ability to explain and make decisions), in order to be referred and used by design personnel to improve design efficiency. The design information needed by the personnel in design field refers to all the information which is produced, collected, referred and consulted by designers or design organizations from the initial concept design to the last detail design phase of the whole design process.

The present situation of the present design information application has the following disadvantages:

\section{A. Treatment effect is low}

Designers rely on artificial to search and design every design information which is relevant to the subject matter, which causes a waste of time.

\section{B. Sorting and application are difficult}

There are many different kinds of design information, the characteristics and properties of which are vary. The induction, stylist and the subsequent application of the information has no common format or management pattern, which makes design information cannot be effectively used.

\section{Information preservation is not easy}

Design information are most in written and graphic forms. With the increase of frequency and the damage to the materials, design information is often unable to be saved for a long time. In addition, the traditional collecting method is a lack of computer and digital auxiliary, which is prone to failure and error.

Based on e-commerce, from the perspective of industrial designers, this paper develops the appropriate design support tools, which cannot only help designers convenient search and manage design information effectively, but also can improve the communication efficiency of design information both inside and outside the enterprise.

\section{THE INFLUENCE OF E-COMMERCE TO CONSUMERS}

E-commerce usually refers to achieve the comprehensive electronic of the whole business and trade activities around the world, under the Internet environment, based on the server and the browser applications, which covers any form of commercial trade pattern in which each party of the trade does not approach face to face exchange or face to face interview. From the aspect of technology, e-commerce can be defined as: e-commerce is a set of more than one kind of technology, including exchanging data, accessing data (such as a sharing database or electronic bulletin boards), and automatic data capturing, etc.

The consumption behavior depending on the Internet is a new human activity. In the process of consumption, consumers is in an active status. On electronic shopping platform, consumer can switch to a different electrical business in a few seconds. They can compare, identify and deal with information and search for what they really need according to their requirements. The consumption can be done whenever and wherever they like, which makes consumption be unprecedented free. E-commerce also reduces the supply links of intermediate channels and the competition of merchants to fight for consumer groups, which provides enough attractive prices for consumers. On the other hand, e-commerce is completely done on the virtual interface via the Internet, which brings new problems for consumer behavior.

As shown in Fig .1, the online shopping process is more complicated than that of physical shopping places, which has higher requests on consumers' knowledge and cognitive skills. Consumers have a large amount of information to process and identify, and complicated operation process needs reasonable guidance, accounts need a wide range of management. What' $\mathrm{s}$ more, authenticity of network makes consumers be lack of physical perception of products, while the consumer experience in stores are more "real" . 


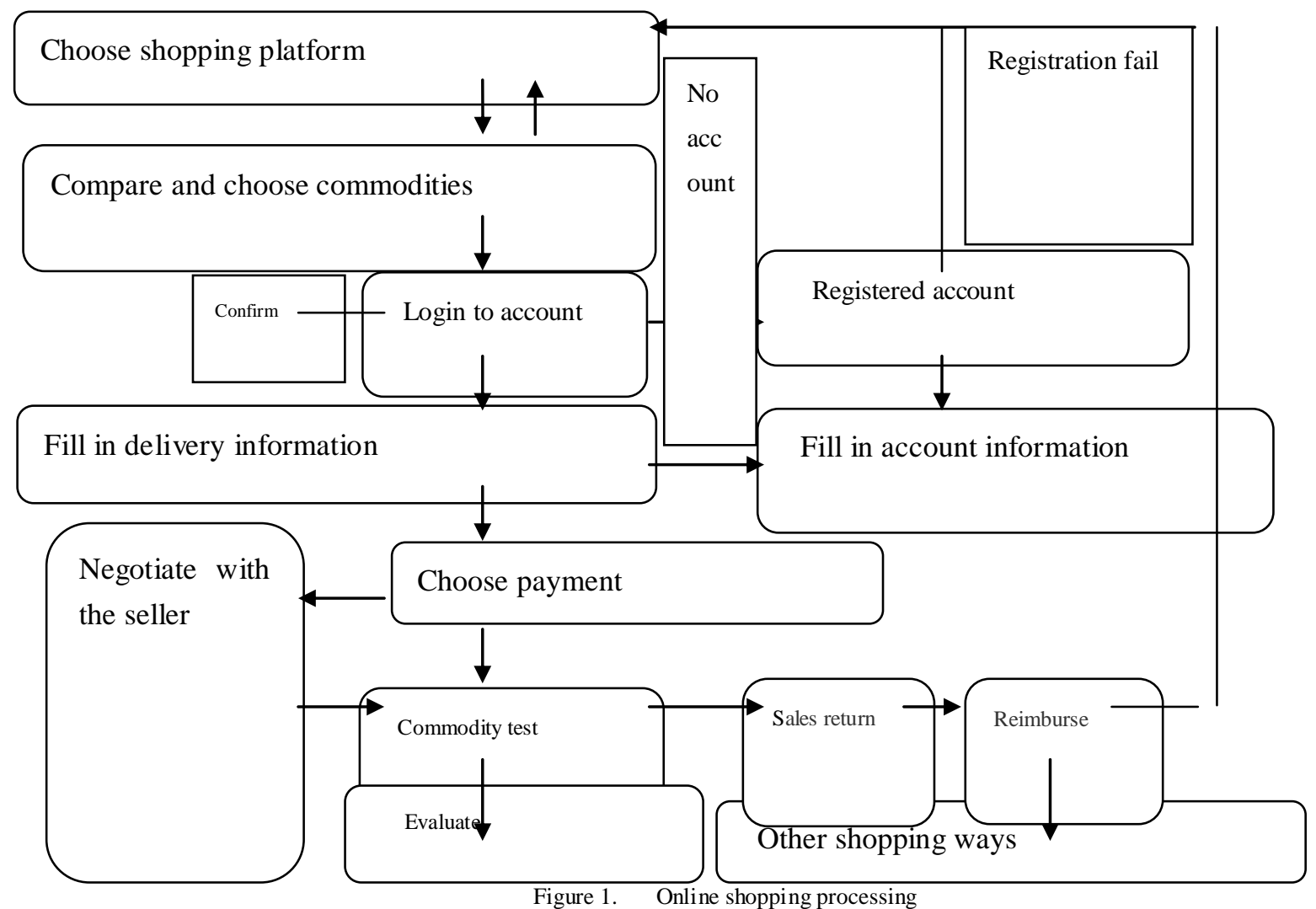

\section{THE OPPORTUNITY AND DEVELOPMENT OF} INDUSTRIAL DESIGN IN E-COMMERCE ERA

Industrial designer has been committed to become the bridge between consumers and businesses, to solve the conflicts of interests between them to achieve win-win results: to enable consumers to get satisfied products and enterprises to be benefit in production activities, and create value for the society. E-commerce has changed the forms of activity and relationships between consumers and businesses, in which the following three aspects are the most significant --- network data, network media and network products. Through combining with e-commerce, industrial design can bring effective, suitable and pleasant experience for consumers.

As shown in Fig .2, in traditional marketing strategy, in view of the packaging, transport, display, exhibition, publicity and marketing links of product, designers need to meet the functional requirements and the aesthetic needs of consumers, which derives a multitude of design fields.

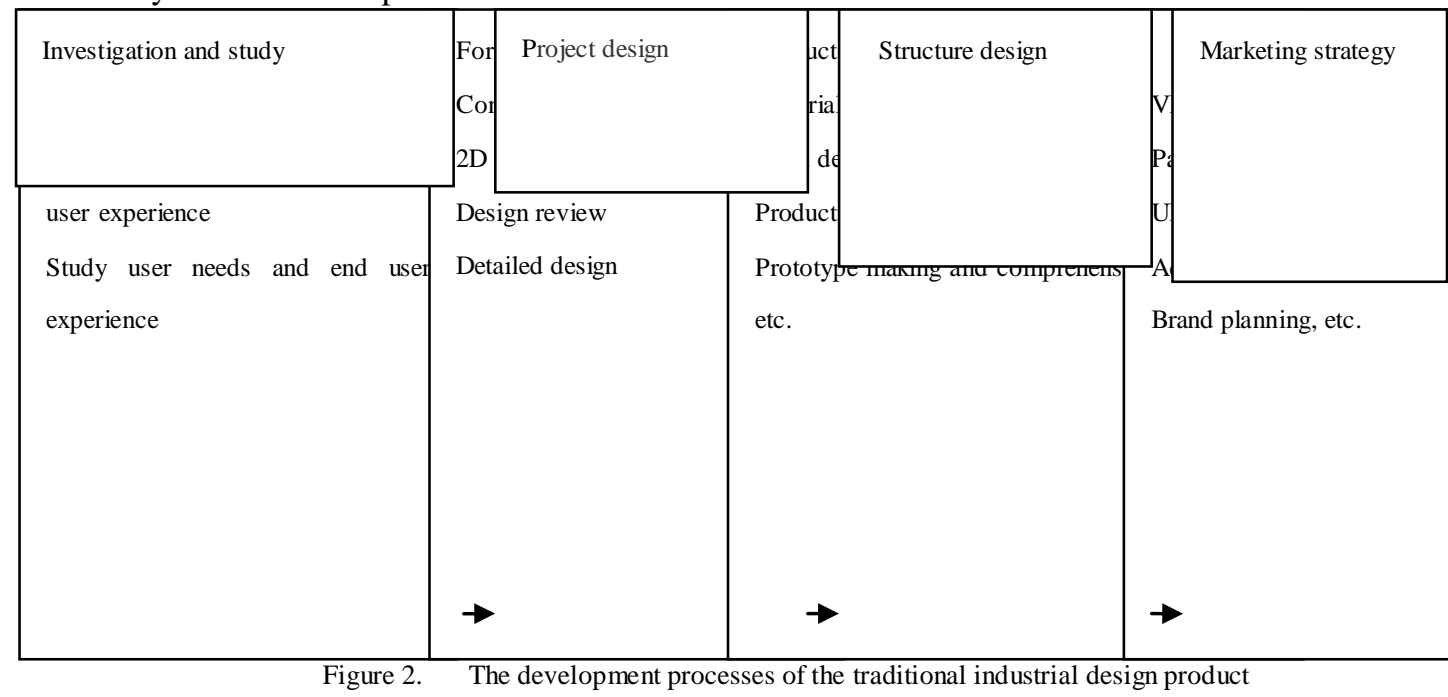

\section{THE NEW EXPLORATION OF PRODUCT DESIGN BASED ON E-COMMERCE PLATFORM}

We hope that, from the perspective of industrial designers, develop appropriate design support tools, which does not only help designers conveniently search and manage design information effectively, but also also improves the communication efficiency of the design information both inside and outside the enterprise. We also hope to use parts of the concept of e-commerce to help designers improve design efficiency and competitiveness. Adding various modules can expand its functionality, which makes it can be used in a variety of different areas and increases bi-directional communication. 
A same product database is used to access, at which time, all the staff can get the modified data by the same product database at the right time. Develop a set of integrated solution which contains product design automation principle, methodology, and system, in order to effectively storage, collect, transfer, control, share, evaluate and track enterprise product design resources.

With the combination with the network data, interfaces, products and other factors derived by electronic commerce, industrial design has many new fields and methods which are worth exploring and researching, as shown in Fig .3. In the future, designers can more accurately understand the product market positioning and users' demands and attitudes for products. It is necessary to put more power to establish a high efficient and pleasant communication medium between users and enterprises and to explore new business feasibility.

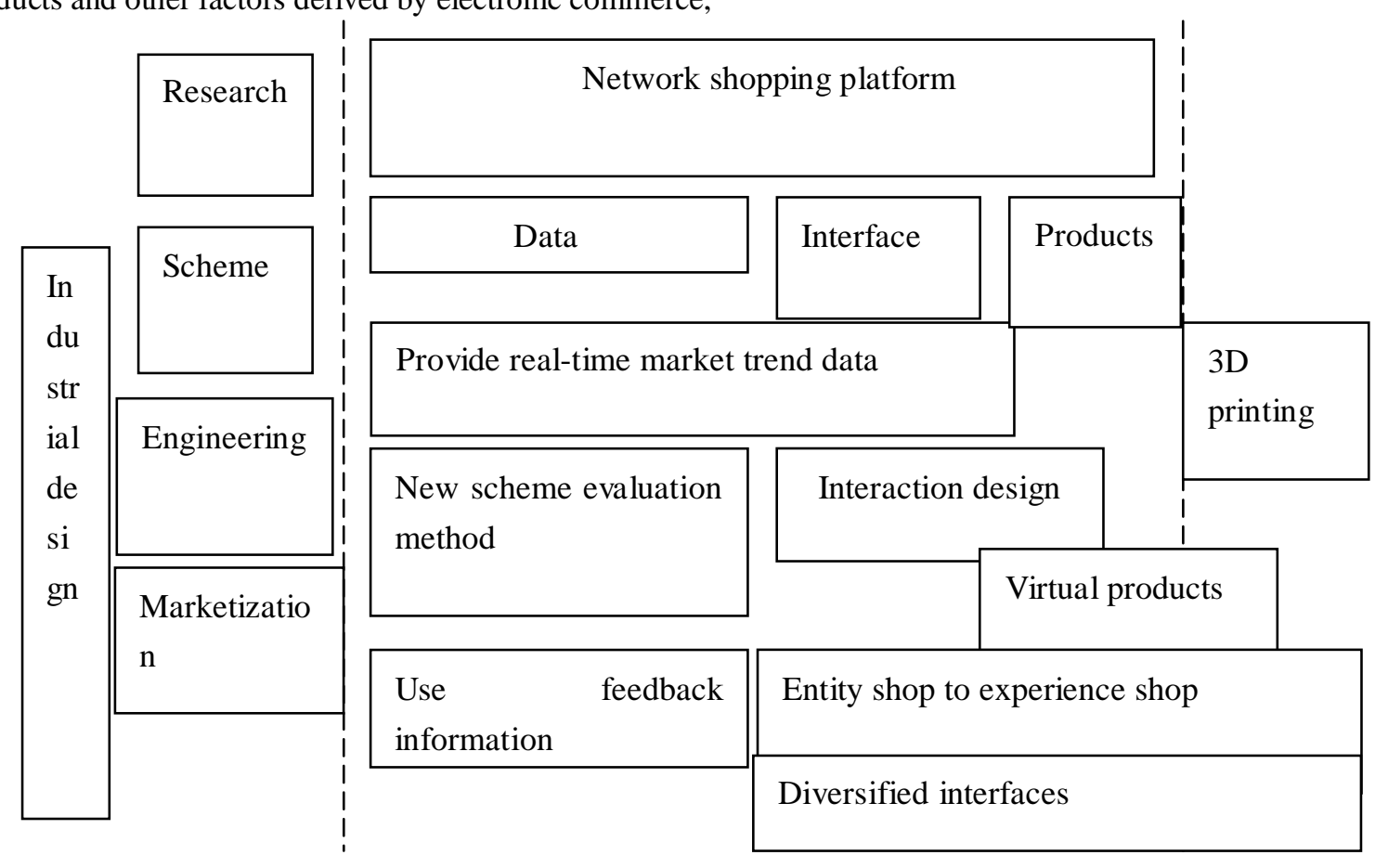

Figure 3. Industrial design development area based on the network shopping

\section{CONCLUSION}

E-commerce platform teaching mode does not only break the existing limitations of the industrial environment and the development of government planning of its own city, it also brings industrial design to the direction to combining the global economy and industry assets and gradually makes the subject to be the "strong subject" with a strong adaptability feature. Students upload their work to the Internet, enterprises can find out satisfied product innovation projects through the websites and communicate and discuss directly with students, which will inevitably enlarge the development of industrial design. In the process of contact with enterprises, students will have deeper understand to the related disciplines. Teachers of industrial design should actively use the subject to make our graduates become the real design talents with competitiveness, which is the road of sustainable development the industrial design should go. As it is described in this paper, the industrial design will have a effective development only when it combines with e-commerce platform.

\section{REFERENCE}

[1] Hertenstein J H, Platt M B, Veryzer R W. The Impact of Industrial Design Effectiveness on Corporate Financial Performance*[J]. Journal of Product Innovation Management, 2005, 22(1):3-21.

[2] Yang, Ming Ying, M. You, and F. C. Chen. "Competencies and qualifications for industrial design jobs: implications for design practice, education, and student career guidance." Design Studies 26.2(2005): 155-189.

[3] Bakker, C. A. "Environmental Information for Industrial Designers." Industrial Design Engineering (1995).

[4] Bakker, C. A. "Environmental Information for Industrial Designers." Industrial Design Engineering (1995).

[5] Hertenstein, Julie H., M. B. Platt, and R. W. Veryzer. "The Impact of Industrial Design Effectiveness on Corporate Financial Performance*." Journal of Product Innovation Management 22.1(2005):3-21

[6] Tjalve, E. "A Short Course in Industrial Design." Journal of Clinical Pathology 44.12(1979):1039.

[7] Fiorentino M, Amicis R D, Monno G, et al. Spacedesign: a mixed reality workspace for aesthetic industrial design[C]// Mixed and Augmented Reality, 2002. ISMAR 2002. Proceedings. International Symposium on. IEEE, 2002:86-318.

[8] Tovey, Michael. "Drawing and CAD in industrial design." Int.j.design Studies 10.89(1989):24-39.

[9] Ramirez M. Sustainability in the education of industrial designers: the case for Australia[J]. International Journal of Sustainability in Higher Education, 2006, 7(2):189-202(14).

[10] Roberge, D. M., Gottsponer, M., Eyholzer, M., \& Kockmann, N. (2009). Industrial design, scale-up, and use of microreactors. Chimica Oggi, 27, 8-11.

[11] Giannini, Franca, and M. M. G. Podehl. "Aesthetic-driven tools for industrial design." Journal of Engineering Design 17.3(2006):193-215.

[12] Pedgley, Owain. "Influence of-Stakeholders on Industrial Design Materials- and Manufacturing Selection." International Journal of Design 3.1(2009):1-15. 